\title{
Comparison of counter-current immunoelectrophoresis, latex agglutination, and radioimmunoassay in detection of soluble capsular polysaccharide antigens of Haemophilus influenzae type $\mathrm{b}$ and Neisseria meningitidis of groups A or $\mathrm{C}$
}

\author{
MAIJA LEINONEN AND HELENA KÄYHTY \\ From the Department of Medical Microbiology, University of Oulu, Oulu, and Central Public Health \\ Laboratory, Helsinki, Finland
}

SUMMARY Three serological methods, radioimmunoassay (RIA), latex agglutination (LX), and counter-current immunoelectrophoresis (CIEP), for sensitivity in the detection of the capsular polysaccharide antigen of Haemophilus influenzae type b or Neisseria meningitidis groups A and C were compared. RIA was consistently the most sensitive, LX the next, and CIEP the least sensitive. When RIA and LX were used to test cerebrospinal fluid (CSF) samples of patients with meningitis, they gave very similar results. In only two out of 47 samples, in which RIA detected one of the three antigens, was the amount of the specific polysaccharide too low to be detected by LX. By the serological methods we could detect evidence of specific pathogen in 49 samples, including nine from patients who had received intensive antimicrobial treatment for up to three days and from whom specimens yielded no bacteria on culture. The reactions were specific in all cases except two out of 47 tests positive by LX. From these two CSF samples $N$. meningitidis group B could be cultivated, whereas the LX was recorded positive for $N$. meningitidis of group A in one case, and of group $\mathrm{C}$ in the other. The nonspecific reactions could be due to antibodies to bacterial components other than the capsular polysaccharide.

Bacterial meningitis is usually caused by bacteria with acidic polysaccharide capsules. These bacteria shed large amounts of the capsular material in their growth medium, including body fluids, during infection. The recent development of sensitive methods to detect these polysaccharides has led to the realisation that determination of the bacterial antigen could be used as an aid to rapid diagnosis of these diseases. Counter-current immunoelectrophoresis (CIEP) (Greenwood et al., 1971), latex agglutination (LX) (Severin, 1972; Leinonen and Herva, 1977), and radioimmunoassay (RIA) (Siskind et al., 1967; O'Reilly et al., 1975; Käyhty et al., 1977) have been used for this purpose. The sensitivities of each assay have been reported but not compared in the same laboratory. We therefore compared the three methods using solutions of

Received for publication 10 May 1978 the pure polysaccharides in respect of Haemophilus influenzae type $\mathrm{b}$ and Neisseria meningitidis groups $A$ and $C$, for which all three assays have been standardised. We also compared the two most sensitive assays for their ability to aid diagnosis using 86 samples of cerebrospinal fluid (CSF) from patients with meningitis.

\section{Material and methods}

CEREBROSPINAL FLUID

From 86 patients with purulent meningitis 86 samples were sent to the Central Public Health Laboratory for antigen determination in 1974-76. Because of an epidemic of group A meningococcal meningitis in Finland in 1973-75, there was a preponderance of cases caused by $N$. meningitidis group A. Bacterial cultures of CSF, blood, and swabs from the nasopharynx were performed in local laboratories, and the identity of the isolates 1172 
was confirmed as previously described by Peltola et al. (1977a and b). In 71 patients a positive CSF culture was obtained. The finding of $H$. influenzae type b (1 case) or $N$. meningitidis group A (5 cases) in the nasopharynx in patients with clinically typical meningitis was considered indicative of aetiology because the carrier rates for both these organisms were very low in the population at this time (A. Sivonen, personal communication). In three of these cases paired sera were available for antibody determination and showed a specific antibody rise (RIA) in each case (Peltola et al., 1977b). In one case, diagnosis was based only on a specific rise in anti-MenC antibodies (RIA). In eight cases the disease was considered to be of viral origin.

Capsular polysaccharides for the calibration of the assays were the same preparations that we used previously (Käyhty et al., 1977). The radioiodinated polysaccharide antigens for RIA were also the same as before (Käyhty et al., 1977; Mäkelä et al., 1977).

\section{ANTISERA}

Antisera for $N$. meningitidis groups $\mathrm{A}$ and $\mathrm{C}$ were purchased from Difco Laboratories (Detroit, Michigan). The antiserum for $\boldsymbol{H}$. influenzae type $\mathrm{b}$ used in RIA was purchased from Difco and that used in CIEP and LX from Hyland (Division of Travenol Laboratories, Inc, Costa Mesa, California, USA).

\section{SEROLOGICAL METHODS}

Counter-current immunoelectrophoresis (Greenwood et al., 1971) was carried out in $1 \%$ agarose gel using barbital buffer, pH 8.6 , ionic strength 0.05 . The electrophoresis was run for one hour at room temperature using Hyland Counterelectrophoresis Power Supply with a constant current of $30 \mathrm{~mA}$. The latex reagents were prepared and the LX assay was performed as described earlier (Severin, 1972; Leinonen and Herva, 1977). RIA was likewise performed as previously described (Käyhty et al., 1977).

\section{Results}

Testing with the individual polysaccharides (Table 1) showed that RIA was the most sensitive, LX the next, and CIEP the least sensitive of the methods. All assays were most sensitive with the $H$. influenzae type $b$ polysaccharide, which we could detect at $a$ concentration of $0.5 \mathrm{ng} / \mathrm{ml}$ by RIA, of $5 \mathrm{ng} / \mathrm{ml}$ by LX, and of $20 \mathrm{ng} / \mathrm{ml}$ by CIEP. The detection limits of the meningococcal polysaccharides were two to 10 times higher. All methods gave positive results
Table 1 Sensitivity of counter-current immunoelectrophoresis (CIEP), latex agglutination test $(L X)$, and radioimmunoassay $(R I A)$ for detection of capsular polysaccharides of $\mathrm{H}$. influenzae type $b$ or N. meningitidis group $A$ or $C$

\begin{tabular}{llll}
\hline Method & \multicolumn{3}{l}{ Capsular polysaccharide detected $(\mathrm{ng} / \mathrm{ml})$} \\
\cline { 2 - 4 } & $\begin{array}{l}\text { H. influenzae } \\
\text { type } b\end{array}$ & \multicolumn{2}{l}{ N. meningitidis } \\
\cline { 2 - 4 } & & Group A & Group C \\
\hline CIEP & 20 & 50 & 75 \\
LX & 5 & 10 & 25 \\
RIA & 0.5 & 2 & 5 \\
\hline
\end{tabular}

up to the highest concentration of polysaccharide $(10 \mu \mathrm{g} / \mathrm{ml})$ tested. The general finding in earlier studies was similar: LX compared with CIEP was more sensitive (Severin, 1972; Ingram et al., 1973; Leinonen and Herva, 1977) or equal (Coonrod and Rytel, 1972; Whittle et al., 1974), whereas RIA showed the best sensitivity (O'Reilly et al., 1975; Käyhty et al., 1977). We therefore used only RIA and LX to study the clinical specimens.

The results of the examination of CSF samples from 86 meningitis patients are set out in three groups in Table 2 . The first two groups are samples from patients whose meningitis was caused by one of the three organisms ( $H$. influenzae type b, $N$. meningitidis groups $\mathrm{A}$ or $\mathrm{C}$ ) that we could detect with the RIA and LX assays. The first group includes all 43 samples from which the specific organism could be grown, whereas the second group consists of 23 samples that were negative on culture, in most cases because they were collected from one to several days after the beginning of intensive antimicrobial treatment. The third group contains samples from patients whose meningitis was of viral origin or was caused by $N$. meningitidis groups B or Y, for which we had no specific RIA or LX assay.

In the first group, most samples (36 out of 43) were positive in both RIA and LX, while three $(7 \%)$ were negative in both, and four were positive in one or other only. An examination of these four cases did not reveal the reason for the discrepant findings. In the samples that were positive by RIA only, the amount of polysaccharide in the sample $(\geqslant 100 \mathrm{ng} / \mathrm{ml}$ of the $H$. influenzae, $50 \mathrm{ng} / \mathrm{ml}$ of the $N$. meningitidis group $\mathrm{C}$ polysaccharide) was well within the detection range of the LX assay. The LX-positive, RIA-negative results could reflect a reaction caused by other than antipolysaccharide antibodies adsorbed to the LX reagent (see Discussion). 
Table 2 Detection by radioimmunoassay $(R I A)$ or latex agglutination $(L X)$ of specific capsular polysaccharide in cerebrospinal fluid (CSF) of meningitis patients

\begin{tabular}{|c|c|c|c|c|c|c|c|c|}
\hline \multirow[t]{2}{*}{ CSF samples } & \multirow[t]{2}{*}{ Meningitis caused by* } & \multirow{2}{*}{$\begin{array}{l}\text { No. of } \\
\text { patients }\end{array}$} & \multirow{2}{*}{$\begin{array}{l}\text { No. received } \\
\text { antibiotic } \\
\text { before } \\
\text { sample }\end{array}$} & \multicolumn{4}{|c|}{ Specific polysaccharide $\dagger$ in CSF } & \multirow{2}{*}{$\begin{array}{l}\text { Amount of polysac- } \\
\text { charide in positive } \\
\text { samples }(n g / m l \text { by } \\
R I A)(\text { range })\end{array}$} \\
\hline & & & & $\begin{array}{l}+ \text { by } R I A \\
\text { and } L X\end{array}$ & $\begin{array}{c}+b y R I A \\
\text { - by } L X\end{array}$ & $\begin{array}{c}\text { - by } R I A \\
+b y L X\end{array}$ & $\begin{array}{l}\text { - by } R I A \\
\text { and } L X\end{array}$ & \\
\hline $\begin{array}{l}\text { Group I: } \\
\text { specific disease, } \\
\text { culture-positive } \\
\text { samples }\end{array}$ & $\begin{array}{l}H . \text { influenzae type b } \\
N . \text { meningitidis group A } \\
N . \text { meningitidis group C } \\
\text { Total }\end{array}$ & $\begin{array}{r}13 \\
27 \\
3 \\
43\end{array}$ & $\begin{array}{l}0 \\
1 \\
0 \\
1\end{array}$ & $\begin{array}{r}11 \\
23 \\
2 \\
36= \\
84 \%\end{array}$ & $\begin{array}{l}1 \\
0 \\
1 \\
2\end{array}$ & $\begin{array}{l}1 \\
1 \\
0 \\
2\end{array}$ & $\begin{array}{l}0 \\
3 \\
0 \\
3= \\
7 \%\end{array}$ & $\begin{array}{l}6.0-\geqslant 100 \\
40-\geqslant 1000 \\
50-\geqslant 1000\end{array}$ \\
\hline $\begin{array}{l}\text { Group II: } \\
\text { specific disease, } \\
\text { culture-negative } \\
\text { samples }\end{array}$ & $\begin{array}{l}H . \text { influenzae type b } \\
N . \text { meningitidis group A } \\
N . \text { meningitidis group C } \\
\text { Total }\end{array}$ & $\begin{array}{r}6 \\
12 \\
5 \\
23\end{array}$ & $\begin{array}{r}6 \\
9 \\
5 \\
20\end{array}$ & $\begin{array}{c}2 \\
2 \\
3 \\
7= \\
30 \%\end{array}$ & $\begin{array}{l}2 \\
0 \\
0 \\
2\end{array}$ & $\begin{array}{l}\mathbf{0} \\
\mathbf{0} \\
\mathbf{0} \\
\mathbf{0}\end{array}$ & $\begin{array}{c}2 \\
10 \\
2 \\
14= \\
60 \%\end{array}$ & $\begin{array}{c}3 \cdot 5-43 \\
16 \text { and } 40 \\
21-220\end{array}$ \\
\hline $\begin{array}{l}\text { Group III: } \\
\text { other disease }\end{array}$ & $\begin{array}{l}N . \text { meningitidis group B } \\
N . \text { meningitidis group Y } \\
\text { virus } \\
\text { Total }\end{array}$ & $\begin{array}{r}11 \\
1 \\
8 \\
20\end{array}$ & $\begin{array}{l}4 \\
0 \\
0 \\
4\end{array}$ & $\begin{array}{l}\mathbf{0} \\
\mathbf{0} \\
\mathbf{0} \\
\mathbf{0}\end{array}$ & $\begin{array}{l}\mathbf{0} \\
\mathbf{0} \\
\mathbf{0} \\
\mathbf{0}\end{array}$ & $\begin{array}{l}2+ \\
0 \\
0 \\
2\end{array}$ & $\begin{array}{r}9 \\
1 \\
8 \\
18\end{array}$ & $\frac{-}{-}$ \\
\hline
\end{tabular}

* Based on culture of CSF or blood or, in a few cases, nasopharyngeal samples, and specific antibody rise in paired sera, in conjunction with typical clinical picture.

†Specific polysaccharide = capsular polysaccharide of bacterial type or group of causative organism.

$¥$ Nonspecific reactions: one positive for $N$. meningitidis group $\mathrm{A}$, one positive for $N$. meningitidis group C.

Among the 23 culture-negative samples (group II, Table 2) the specific polysaccharide could still be detected in nine $(40 \%)$ by RIA or in seven $(30 \%)$ by LX. In the two CSF samples from patients with $H$. influenzae type $\mathrm{b}$ meningitis that were positive by RIA only, there was 3.5 and $5 \mathrm{ng} / \mathrm{ml}$ polysaccharide, respectively, and thus below the detection limit of the LX assay. Samples from meningitis caused by $N$. meningitidis group $\mathrm{A}$, on the one hand, and $N$. meningitidis group $\mathrm{C}$ or $H$. influenzae type $\mathrm{b}$ on the other, seem to differ. Among the latter, the capsular polysaccharide could be detected after antibiotic treatment in seven out of 11 samples, whereas only one out of nine such samples was positive for $N$. meningitidis group $A$ polysaccharide $(P<0.05)$. In fact a slow elimination of $H$. influenzae type b polysaccharide has been described before and was connected with a poor antibody response to this antigen in infancy (O'Reilly et al., 1975; Granoff et al., 1977). Also the $N$. meningitidis group $\mathrm{C}$ polysaccharide is a poor immunogen in infants (Gold et al., 1975) whereas that of group $\mathbf{A}$ is definitely better (Mäkelä et al., 1977).

In all the above samples (patient groups I and II) the serological findings were specific, so that the antigen detected corresponded with the organism found on culture and/or suggested by antibody determination.

The third group consists of 20 CSF samples, which would not be expected to be positive in the specific serological tests applied because they came from patients with serous meningitis (8) or purulent meningitis caused by $N$. meningitidis groups B or Y (12). RIA was indeed negative in all of these samples, but two positive $L X$ reactions were seen (both in samples from which $N$. meningitidis group B had been cultivated). One of these nonspecific LX reactions was indicative of $N$. meningitidis group A, the other of group C.

\section{Discussion}

How useful is antigen determination in the diagnosis of bacterial meningitis? Firstly, the severity of the condition favours the use of any additional methods that could appreciably increase the number of positive findings. In this series the correct antigen was detected by RIA in $40 \%$ (9 out of 23) and by LX in $30 \%$ ( 7 of 23 ) of culture-negative CSF samples. In nearly all these cases the samples were negative on culture because intensive antimicrobial treatment had been started before sampling, and the amount of bacterial antigen present was relatively low. It has been shown elsewhere that the longer the treatment lasts, the less antigen is left (Granoff et al., 1977). Under other conditions, for example, in areas less experienced in the prompt taking and correct handling of specimens for CSF culture, or where distances to the laboratory are greater, there would be more negative samples on culture but they would contain large amounts of bacterial antigen. Among such samples, the serological demonstration of antigen by either RIA or LX 
would be expected to succeed in approximately $90 \%$ of cases. However, bacterial culture should not be neglected for antigen determination-in three cases $(7 \%)$ the latter was negative by both RIA and LX although culture was positive. We suspect that these samples were taken very early in the course of the disease when the number of bacteria in the CSF was low, but we cannot verify this interpretation because of a lack of accurate records of the timing of the samples. An equally compelling reason for culture is the importance of obtaining the bacteria for antibiotic sensitivity determination, especially with the now increasing resistance of $H$. influenzae (Thomas et al., 1974).

The second and, in most instances, main argument for antigen determination is the time factor. All three serological methods produce results more quickly than culture. In this respect LX is the best test for it can be performed literally as a bedside assay, while CIEP requires 15 to 60 minutes in the laboratory, and RIA two to three hours. In the present series a standard overnight incubation was used in the RIA, but we have shown previously that although shortening the incubation time decreases the sensitivity slightly it does not influence the result (Käyhty et al., 1977).

The value of antigen determination as a routine method would be increased if there were assays for as many potential CSF pathogens as possible. In children 3 months to 5 years old, the assays tested here would cover the majority of cases of purulent meningitis $(60 \%$ in Finland in 1977(Peltola and Mäkelä, to be published)) whereas in the neonatal period streptococci and enteric bacteria prevail, and in older patients $H$. influenzae is rare. The capsular polysaccharide of $N$. meningitidis group B is a poor immunogen, and it is difficult to develop serological assays for it. With a good antiserum (for example, serum produced in the horse (Sivonen et al., 1977)) CIEP can be positive (Feldman, 1977) and also a latex reagent can be produced (Leinonen, in preparation). These assays have not yet been tested for sensitivity sufficiently to allow a comparison with the assays used here. Both CIEP and LX based on a multivalent capsular polysaccharide antiserum have revealed pneumococcal antigen in CSF and also in patient serum (Coonrod and Rylko-Bauer, 1976).

SPECIFICITY OF SEROLOGICAL ASSAYS All the assays use essentially the same kind of antiserum, produced in animals by immunisation with whole bacteria and probably containing antibodies to many other bacterial components besides the capsular polysaccharide. A purer immunogen could not be used because these polysaccharides are poorly immunogenic in animals. The specificity of RIA is increased by the radioactive polysaccharide whose specific binding to the antiserum is prevented by the bacterial polysaccharide to be assayed. All the 47 RIA-positive reactions in this series were specific. CIEP measures precipitation of soluble electronegative material only and is therefore also expected to be rather specific for capsular polysaccharide but false-positive and cross-reactions have been described with commercial antimeningococcal sera (Shackelford et al., 1974).

The LX agglutination might be expected to be least specific. However, among the 86 CSF samples tested we found only two that gave an apparently nonspecific positive reaction in the LX assay, whereas a specific $L X$ reaction (corresponding with the causative agents otherwise identified) was seen in 45 samples. The two nonspecific LX reactions indicated $N$. meningitidis group A (1 case) or group $C$ (1 case) and occurred in samples positive for $N$. meningitidis group B. We think that they could have been caused by antibodies directed to bacterial components other than the capsular polysaccharide. This could also explain the two CSF samples that were negative in RIA but positive in LX (one for $H$. influenzae type $\mathrm{b}$, one for $N$. meningitidis group A). These latter two reactions were, however, specific for the organism identified on culture. If this interpretation of the origin of nonspecific reactions is correct, they can be expected mainly between closely related bacteria likely to share many antigens. Important distinctions in terms of treatment are those between haemophilus and $N$. meningitidis or $D$. pneumoniae, for haemophilus must not be treated with penicillin. In this series we had 19 cases of $H$. influenzae meningitis, of which 14 were positive by $L X$ for the specific antigen, none giving misleading nonspecific reactions.

It seems that the LX assay is an important assay in every hospital to which patients with purulent meningitis might be sent. It is easy to perform and read and no complex equipment is required. RIA is demanding in respect of reagents since the radioactive antigen has to be prepared and standardised every two months. The LX reagents are stable for at least six months in the refrigerator and do not need standardisation or controls at the time of testing. Unfortunately, however, the LX reagents are not commercially available. In Finland they are prepared and provided through the Public Health Laboratory system, and this could be followed in other countries.

These studies were supported in part by the United 
States Public Health Service Contract Number 1A1 52502 from the National Institute of Allergy and Infectious Diseases. We are grateful to Mrs Eeva-Liisa Heikkinen, Mrs Aino Siukonen, and Miss Raija Keijama for skilful technical assistance.

\section{References}

Coonrod, J. D., and Rylko-Bauer (1976). Latex agglutination in the diagnosis of pneumococcal infection. Journal of Clinical Microbiology, 4, 168-174.

Coonrod, D., and Rytel, M. W. (1972). Determination of aetiology of bacterial meningitis by counterimmunoelectrophoresis. Lancet, 1, 1154-1156.

Feldman, W. E. (1977). Relation of concentrations of bacteria and bacterial antigen in cerebrospinal fluid to prognosis in patients with bacterial meningitis. New England Journal of Medicine, 296, 433-435.

Gold, R., Lepow, M. L., Goldschneider, I., Draper, T. L., and Gotschlich, E. C. (1975). Clinical evaluation of group $\mathbf{A}$ and group $\mathrm{C}$ meningococcal polysaccharide vaccines in infants. Journal of Clinical Investigation, 56, 1536-1547.

Granoff, D. M., Congeni, B., Baker, R., Jr., Ogra, P., and Nankervis, G. A. (1977). Countercurrent immunoelectrophoresis in the diagnosis of Haemophilus influenzae type b infection. American Journal of Diseases of Children, 131, 1357-1362.

Greenwood, B. M., Whittle, H. C., and DominicRajkovic, O. (1971). Counter-current immunoelectrophoresis in the diagnosis of meningococcal infections. Lancet, 2, 519-521.

Ingram, D. L., O'Reilly, R., Anderson, P., and Smith, D. H. (1973). Detection of the capsular polysaccharide of Haemophilus influenzae type b in body fluids. In Hemophilus influenzae, edited by S. H. W. Sell and D. T. Karzon, pp. 37-43. Vanderbilt University Press, Nashville, Tennessee.

Käyhty, H., Mäkelä, P. H., and Ruoslahti, E. (1977). Radioimmunoassay of capsular polysaccharide antigens of groups $\mathrm{A}$ and $\mathrm{C}$ meningococci and Haemophilus influenzae type $\mathrm{b}$ in cerebrospinal fluid. Journal of Clinical Pathology, 30, 831-833.

Leinonen, M., and Herva, E. (1977). The latex agglutination test for the diagnosis of meningococcal and Haemophilus influenzae meningitis. Scandinavian Journal of Infectious Diseases, 9, 187-191.

Mäkelä, P. H., Peltola, H., Käyhty, H., Jousimies, H., Pettay, O., Ruoslahti, E., Sivonen, A., and Renkonen,
O.-V. (1977). Polysaccharide vaccines of group A Neisseria meningitidis and Haemophilus influenzae type b: A field trial in Finland. Journal of Infectious Diseases, 136, S43-S50.

O'Reilly, R. J., Anderson, P., Ingram, D. L., Peter, G., and Smith, D. H. (1975). Circulating polyribophosphate in Hemophilus influenzae type b meningitis. Correlation with clinical course and antibody response. Journal of Clinical Investigation, 56, 1012-1022.

Peltola, H., Käyhty, H., Sivonen, A., and Mäkelä, P. H. (1977a). Haemophilus influenzae type b capsular polysaccharide vaccine in children: a double-blind field study of 100,000 vaccinees 3 months to 5 years of age in Finland. Pediatrics, 60, 730-737.

Peltola, H., Mäkelä, P. H., Käyhty, H., Jousimies, H., Herva, E., Hällström, K., Sivonen, A., Renkonen, O.-V., Pettay, O., Karanko, V., Ahvonen, P., and Sarna, S. (1977b). Clinical efficacy of meningococcus group A capsular polysaccharide vaccine in children three months to five years of age. New England Journal of Medicine, 297, 686-691.

Severin, W. P. J. (1972). Latex agglutination in the diagnosis of meningococcal meningitis. Journal of Clinical Pathology, 25, 1079-1082.

Shackelford, P. G., Campbell, J., and Feigin, R. D. (1974). Countercurrent immunoelectrophoresis in the evaluation of childhood infections. Journal of Pediatrics, 85, 478-481.

Siskind, G. W., Paul, W. E., and Benacerraf, B. (1967). The use of radioactively labeled SIII to study the blood clearance and the immune response of mice to pneumococcal polysaccharides. Immunochemistry, 4 455-465.

Sivonen, A., Renkonen, O.-V., and Robbins, J. B. (1977). Use of antiserum agar plates for serogrouping of meningococci. Journal of Clinical Pathology, 30, 834-837.

Thomas, W. J., McReynolds, J. W., Mock, C. R., and Bailey, D. W. (1974). Ampicillin resistant Hemophilus influenzae meningitis (Letter). Lancet, $1,313$.

Whittle, H. C., Tugwell, P., Egler, L. J., and Greenwood, B. M. (1974). Rapid bacteriological diagnosis of pyogenic meningitis by latex agglutination. Lancet, 2, 619-621.

Requests for reprints to: Miss Maija Leinonen, Department of Medical Microbiology, University of Oulu, Kajaanintie 46D, SF-90220 Oulu 22, Finland. 